\title{
Variations in the management of fibromyalgia by physician specialty: rheumatology versus primary care
}

This article was published in the following Dove Press journal:

Pragmatic and Observational Research

20 May 2016

Number of times this article has been viewed

\author{
Stephen L Able' \\ Rebecca L Robinson ${ }^{2}$ \\ Kurt Kroenke ${ }^{3,4}$ \\ Philip Mease ${ }^{5,6}$ \\ David A Williams ${ }^{7}$ \\ Yi Chen ${ }^{8}$ \\ Madelaine Wohlreich ${ }^{9}$ \\ Bill H McCarberg ${ }^{10}$ \\ 'US Health Outcomes and Technology \\ Assessment, Global Health Outcomes, \\ Eli Lilly and Company, Indianapolis, \\ IN, USA; ${ }^{2}$ Lilly Research Labs, \\ Global Health Outcomes, Eli Lilly \\ and Company, Indianapolis, IN, \\ USA; ${ }^{3}$ Department of Medicine, \\ Indiana University, ${ }^{4} \mathrm{VA}$ Health \\ Services Research and Development \\ Center for Health Information and \\ Communication, Regenstrief Institute, \\ Indianapolis, IN, USA; ${ }^{5}$ Rheumatology \\ Associates, Division of Rheumatology \\ Clinical Research, Swedish Medical \\ Center, ${ }^{6}$ University of Washington \\ School of Medicine, Seattle, WA, USA; \\ ${ }^{7}$ Chronic Pain and Fatigue Research \\ Center, Michigan Institute for Clinical \\ and Health Research, University of \\ Michigan School of Medicine, Ann \\ Arbor, MI, USA; ${ }^{8}$ inVentiv Health \\ Clinical, Indianapolis, IN, USA; 'USMD \\ Neuroscience, Lilly USA LLC, Eli Lilly \\ and Company, Indianapolis, IN, USA; \\ ${ }^{10}$ Department of Family Medicine, \\ University of California at San Diego \\ School of Medicine, San Diego, CA, \\ USA
}

Correspondence: Stephen L Able Eli Lilly and Company, Lilly Corporate Center, Indianapolis, IN 46285, USA

$\mathrm{Tel}+\mathrm{I} 3172763612$

Fax + I 3172767100

Email able_stephen_!@lilly.com
Purpose: To evaluate the effect of physician specialty regarding diagnosis and treatment of fibromyalgia (FM) and assess the clinical status of patients initiating new treatment for FM using data from Real-World Examination of Fibromyalgia: Longitudinal Evaluation of Costs and Treatments.

Patients and methods: Outpatients from 58 sites in the United States were enrolled. Data were collected via in-office surveys and telephone interviews. Pairwise comparisons by specialty were made using chi-square, Fisher's exact tests, and Student's $t$-tests.

Results: Physician specialist cohorts included rheumatologists $(n=54)$, primary care physicians $(n=25)$, and a heterogeneous group of physicians practicing pain or physical medicine, psychiatry, neurology, obstetrics and gynecology, osteopathy, or an unspecified specialty $(n=12)$. The rheumatologists expressed higher confidence diagnosing FM (4.5 on a five-point scale) than primary care physicians $(4.1)(P=0.037)$. All cohorts strongly agreed that recognizing FM is their responsibility. They agreed that psychological aspects of FM are important, but disagreed that symptoms are psychosomatic. All physician cohorts agreed with a multidisciplinary approach including nonpharmacological and pharmacological treatments, although physicians were more confident prescribing medications than alternative therapies. Most patients reported moderate to severe pain, multiple comorbidities, and treatment with several medications and nonpharmacologic therapies.

Conclusion: Physician practice characteristics, physician attitudes, and FM patient profiles were broadly similar across specialties. The small but significant differences reported by physicians and patients across physician cohorts suggest that despite published guidelines, treatment of FM still contains important variance across specialties.

Keywords: medical specialty, treatment, prospective observational study

\section{Introduction}

Fibromyalgia (FM) is a chronic pain condition, characterized by numerous associated symptoms (eg, widespread pain, fatigue, sleep disturbances, dyscognition), many of which may also be shared with other disorders. A patient satisfies the diagnostic criteria for FM if the following conditions are met: widespread pain index $\geq 7$ and symptom severity scale score $\geq 5$, or widespread pain index 3-6 and symptom severity scale score $\geq 9$; symptoms have been present at a similar level for at least 3 months; and the patient does not have a disorder that would otherwise explain the pain. ${ }^{1}$ Diagnosis of FM is dependent upon patients' reporting of symptoms as there is no objective clinical finding or single widely accepted test with which to confirm diagnosis or gauge the severity of symptoms. As with many forms of chronic pain, there are multiple treatment submit your manuscript | www.dovepress.com Dovepress

http://dx.doi.org/| 0.2 | 47/POR.S7944|
Pragmatic and Observational Research 2016:7 II-20

(c) (i) (5) 2016 Able et al. This work is published by Dove Medical Press Limited, and licensed under Creative Commons Attribution - Non Commercial (unported, v3.0) cC. permission from Dove Medical Press Limited, provided the work is properly attributed. Permissions beyond the scope of the License are administered by Dove Medical Press Limited. Information on how to request permission may be found at: http://www.dovepress.com/permissions.php 
approaches that can be considered, and the clinician often matches the appropriate treatment strategy with the needs of the individual patient. Historically, the management of FM has been heavily concentrated within the purview of rheumatologists (RHMs); ${ }^{2}$ more recently, however, a wider range of physician specialists are being consulted by individuals with FM (eg, primary care physicians [PCPs], psychiatrists, and neurologists). ${ }^{3}$ With accumulating evidence that FM is a disorder of central pain processing/modulation, FM can no longer be categorized as a musculoskeletal disease process, but rather as a pain syndrome maintained by perturbed central nervous system activity. ${ }^{4,5}$

A recent prospective observational study, the RealWorld Examination of Fibromyalgia: Longitudinal Evaluation of Costs and Treatments (REFLECTIONS), was designed to describe burden of illness and treatment patterns in individuals with FM within "real-world" practice settings. ${ }^{6}$ Descriptive analyses of baseline data from the REFLECTIONS study confirmed that the burden of illness was high for patients with FM, and treatment patterns revealed the use of a wide variety of medications (both US Food and Drug Administration [FDA]-approved and offlabel) and a broad sampling of nonpharmacologic treatments often used in combination with medications. Multivariate patient-focused analyses of the REFLECTIONS baseline data comparing the use of FDA-approved medications (eg, duloxetine, pregabalin, and milnacipran) with other medications for the treatment of FM showed physician specialty to be among the strongest determinants of which FM treatment was selected.

The primary purpose of this post hoc analysis was to describe differences between specialties, primarily those from rheumatology and primary care, in: 1) physician and physician-practice characteristics; 2) physician attitudes and beliefs regarding diagnosis and treatment of FM; and 3) physician prescribing behavior as manifested in actual treatment patterns. A secondary purpose of the study was to examine differences in the demographic and clinical profiles of patients treated by physicians from the studied specialties.

\section{Material and methods}

The following is a summary of methodological considerations from the REFLECTIONS study that were deemed pertinent to the understanding of the present manuscript. A more complete description of the REFLECTIONS study methodology is provided in Robinson et al. ${ }^{6}$ The protocol for the REFLECTIONS study was approved by Schulman's Institutional Review Board. All patients provided written informed consent before participating in the study.

\section{Study setting}

REFLECTIONS was an observational, multicenter, realworld study, in which all treatment occurred as part of routine care provided in the course of normal clinical practice. The study included 91 study investigators from 58 practice-based settings in the United States and Puerto Rico. ${ }^{6}$ Potential investigators were identified through lists of investigators with prior experience conducting observational or clinical research; literature searches of physician authors publishing in FM; and referrals from other physicians. Physicians were invited to participate as study investigators on the basis of the average number of patients with FM they saw monthly. Physician recruitment was monitored in an attempt to ensure that the distribution of study physicians reflected the types and rates of physicians seen in actual clinical practice. A total of 54 physicians practicing rheumatology (RHMs) enrolled 1,130 patients, 25 physicians practicing primary care medicine (PCPs) enrolled 271 patients, and a heterogeneous group of 12 physicians practicing either pain or physical medicine $(n=3)$, psychiatry $(n=3)$, neurology $(n=2)$, obstetrics and gynecology $(n=1)$, osteopathy $(n=1)$, or an unspecified specialty ( $\mathrm{n}=2$ ) (OTHERs) enrolled the remaining 299 patients. Enrollment for RHMs (20.9) and OTHERs (24.9) was approximately twice as many patientsper-physician than enrollment for PCPs (10.8). Due to the small sample size $(n=12)$ and heterogeneity of physicians in the group of OTHERs, the results from the OTHERs may preclude meaningful interpretation.

\section{Inclusion/exclusion criteria}

Patients were eligible for REFLECTIONS if they were at least 18 years of age, cognitively able to understand and complete computer-assisted telephone interviews in English or Spanish, and available to participate in the study for 12 months. Patients were invited to participate if, in the opinion of the enrolling physician, they: 1) met diagnostic criteria for FM; 2) were initiating a new treatment for FM; and 3) were under the care of the participating physician at the time of enrollment. New treatment for FM was defined as a prescription for any pharmacologic agent used for the treatment of FM that had not been used in the last 6 months, and thus comprised naïve FM treatment initiators, patients switching from one treatment to another, and patients aug- 
menting an existing treatment regimen. Individuals who were investigators or site personnel directly affiliated with the study, and/or their immediate families, were excluded from the study.

\section{Data collection}

Data were collected by three separate means: a physician survey completed prior to the enrollment of any patients; a patient visit form completed jointly by the patient and physician or practice staff member during the enrollment visit (after the patient had signed the patient informed consent form); and structured interviews conducted with patients via telephone (to collect additional data regarding patient health status and care at baseline and throughout the 12 months of the study) following the enrollment visit. The physician survey provided information regarding physician demographics, practice characteristics, and physician attitudes and opinions regarding the diagnosis and treatment of FM. These attitudes and opinions were assessed by asking physicians to indicate their level of agreement with a battery of statements using a five-point scale $(1=$ completely disagree, $2=$ somewhat disagree, $3=$ neither agree nor disagree, $4=$ somewhat agree, or $5=$ completely agree). The physician survey was specifically created to provide descriptive information for use in the REFLECTIONS study.

The patient visit form was completed jointly by the physician and the patient during the routine office visit when a new pharmacologic treatment was prescribed. Study investigators provided an assessment of each enrolled patient's medical history and treatment plan, including all ongoing, discontinued, and newly started pharmacologic and nonpharmacologic therapies for FM. Patients added their demographic information and a portion of their medical history using the Patient Health Questionnaire-15 to complete the office visit form. No further study-specific physician or on-site patient information was required.

Baseline and follow-up data were used to conduct the longitudinal portion of the primary REFLECTIONS analyses reported in Robinson et al. ${ }^{6}$ Only baseline information, which was gathered within 14 days of study enrollment, was utilized in the analyses reported in this manuscript.

\section{Statistical analysis}

Descriptive statistics were used to characterize current treatment patterns and other patient and physician variables. Means and standard deviations were reported for continuous variables for each of the three specialist groupings; proportions were reported for categorical variables. Pairwise comparisons between physician specialist categories were made using chi-square and Fisher's exact tests for categorical variables and Student's $t$-tests for continuous variables. No adjustments were made for multiple comparisons, as the study objectives were exploratory in nature. No formal hypothesis was tested since there were no well-substantiated priors regarding the expected direction of any potential differences between physician specialties. As such, two-sided tests of significance without adjustment for multiple comparisons were conducted. All analyses were performed using $\mathrm{SAS}^{\circledR}$ Version 9.2 (SAS Institute Inc., Cary, NC, USA).

\section{Results}

Physicians serving as study investigators in the REFLECTIONS observational study averaged 49.5 years of age with an average of 15.6 years in practice, with no notable differences across specialties (Table 1). Patients reported a mean age of 50.4 years and were mostly female and white. Patients enrolled by PCPs were more likely to be Hispanic (42.0\%) than those enrolled by RHMs (4.2\%) or OTHERs (16.7\%).

\section{Diagnosis and treatment of FM}

\section{Physician attitudes and beliefs}

Physicians generally expressed confidence in their ability to diagnose (mean $=4.4$ on a scale of 1 [completely disagree] to 5 [completely agree]) and treat FM with medications (mean =4.3). All cohorts reported agreement on the use of the American College of Rheumatology (ACR) criteria to diagnose FM (mean =4.0), and they agreed that recognizing (mean =4.3) and treating (mean =4.1) FM was their responsibility and that the psychological aspects of FM are important $($ mean $=4.5)$ (Figure $1 \mathrm{~A}$ and $\mathrm{B})$. All physician cohorts disagreed that the FM diagnosis was made in the absence of any other diagnosis (mean $=2.3$ ) and disagreed with the notion that the symptoms of FM were of a psychosomatic origin (mean $=2.2$ ). The RHMs reported significantly $(P=0.037)$ higher ratings than PCPs (4.5 versus 4.1$)$ regarding their levels of confidence in diagnosing FM. The RHMs also reported significantly stronger agreement than OTHERs that they felt limited by the availability of adequate options for treating patients with FM (3.7 versus $2.9, P=0.024)$.

\section{Treatment}

\section{Pharmacologic treatments}

Physicians reported using 182 unique medications for the treatment of FM. ${ }^{6}$ The top five prescribed medications were duloxetine, nonsteroidal anti-inflammatory drugs (NSAIDs), pregabalin, opioids (excluding tramadol), and tramadol. These 
Table I Physician and patient demographics

\begin{tabular}{|c|c|c|c|c|c|c|c|}
\hline \multirow[t]{2}{*}{ Physicians } & \multirow{2}{*}{$\begin{array}{l}\text { Total } \\
\mathrm{N}=9 \text { I }\end{array}$} & \multirow{2}{*}{$\begin{array}{l}\text { RHMs } \\
n=54\end{array}$} & \multirow{2}{*}{$\begin{array}{l}\text { PCPs } \\
n=25\end{array}$} & \multirow{2}{*}{$\begin{array}{l}\text { OTHERs } \\
n=12\end{array}$} & \multicolumn{3}{|l|}{$P$-value } \\
\hline & & & & & $\begin{array}{l}\text { RHMs vs } \\
\text { PCPs }\end{array}$ & $\begin{array}{l}\text { RHMs vs } \\
\text { OTHERs }\end{array}$ & $\begin{array}{l}\text { PCPs vs } \\
\text { OTHERs }\end{array}$ \\
\hline \multicolumn{8}{|l|}{ Age in years } \\
\hline Mean (SD) & $49.5(9.8)$ & 49.1 (9.5) & 48.9 (9.8) & $51.9(11.4)$ & - & - & - \\
\hline \multicolumn{8}{|l|}{ Sex } \\
\hline (\% male) & 72.9 & 73.5 & 66.7 & 83.3 & - & - & - \\
\hline \multicolumn{8}{|c|}{ Years in practice } \\
\hline Mean (SD) & $15.6(9.2)$ & I5.4 (9.7) & $16.7(9.7)$ & I $4.3(5.6)$ & - & - & - \\
\hline Patients & $\begin{array}{l}\text { Total } \\
\mathrm{N}=I, 700\end{array}$ & $\begin{array}{l}\text { RHMs } \\
n=1,130\end{array}$ & $\begin{array}{l}\text { PCPs } \\
n=27 \mid\end{array}$ & $\begin{array}{l}\text { OTHERs } \\
n=299\end{array}$ & $\begin{array}{l}\text { RHMs vs } \\
\text { PCPs }\end{array}$ & $\begin{array}{l}\text { RHMs vs } \\
\text { OTHERs }\end{array}$ & $\begin{array}{l}\text { PCPs vs } \\
\text { OTHERs }\end{array}$ \\
\hline \multicolumn{8}{|l|}{ Age in years } \\
\hline Mean (SD) & 50.4 (II.9) & $50.4(12.0)$ & $52.8(12.2)$ & $48.4(10.9)$ & 0.008 & 0.028 & $<0.001$ \\
\hline \multicolumn{8}{|c|}{ Age $(\%>65$ years $)$} \\
\hline $\mathrm{n}(\%)$ & $159(9.4)$ & $109(9.6)$ & $36(13.3)$ & $14(4.7)$ & - & 0.020 & 0.001 \\
\hline \multicolumn{8}{|l|}{ Female } \\
\hline n (\%) & $\mathrm{I}, 60 \mathrm{I}(94.6)$ & I,07I (95.0) & $25 \mathrm{I}(93.7)$ & $279(93.9)$ & - & - & - \\
\hline Race, n (\%) & & & & & $<0.001$ & $<0.001$ & $<0.001$ \\
\hline White & I,391 (82.9) & $1,017(91.2)$ & $143(53.2)$ & $23 \mid(78.6)$ & & & \\
\hline Hispanic & $209(12.5)$ & $47(4.2)$ & $113(42.0)$ & $49(16.7)$ & & & \\
\hline Other & $78(4.6)$ & $51(4.6)$ & $13(4.8)$ & $14(4.8)$ & & & \\
\hline
\end{tabular}

Note: “-” indicates not significant, $P>0.05$.

Abbreviations: OTHERs, physicians practicing either pain or physical medicine, psychiatry, neurology, obstetrics and gynecology, osteopathy, or an unspecified specialty; PCPs, primary care physicians; RHMs, rheumatologists; SD, standard deviation.

medications were generally the same across physician specialty (Table 2), although with some significant differences in their specific rank orderings. Pregabalin, which is one of the three FDA-approved medications for use in FM, was the most frequently prescribed medication by RHMs (28.8\%) and was prescribed at a significantly higher rate than by PCPs $(12.5 \%)$ or OTHERs (19.1\%). The RHMs also prescribed duloxetine, another of the three FDA-approved medications for use in FM, significantly more often (27.1\%) than PCPs (16.2\%), though significantly less frequently than OTHERs (35.5\%). The other approved FM medication at the time of the study, milnacipran, was less frequently prescribed than pregabalin or duloxetine overall, but again more frequently by RHMs (9.1\%) and OTHERs (13.7\%) than by PCPs (3.3\%). The NSAIDs were the most frequently prescribed medication by PCPs (46.1\%), at a rate approximately twice as often as RHMs (24.4\%) or OTHERs (18.1\%). OTHERs (32.8\%) prescribed opioids significantly more often than did PCPs (19.2\%) despite all physician cohorts rating the evidence in support of using opioids in FM as being modest. The highest ratings of perceived evidence in support of a medication for FM were given to duloxetine and pregabalin across all physician specialties.

\section{Nonpharmacologic treatments}

The most common nonpharmacologic treatments for FM were rest $(91.0 \%)$ and exercise $(89.5 \%)$, followed by heat modalities $(75.5 \%)$ and prayer, relaxation, or meditation (75.2\%). ${ }^{6}$ Patients of RHMs were significantly less likely to receive counseling $(29.6 \%)$ than either patients of PCPs (37.6\%) or OTHERs (46.5\%) (Table 3 ). Patients of RHMs (18.8\%) and OTHERs $(23.4 \%)$ were more likely to have received transcutaneous electrical nerve stimulation unit treatment than patients of PCPs $(11.4 \%)$, whereas patients of PCPs (15.1\%) and OTHERs (12.4\%) were more likely to have received acupuncture than patients of RHMs $(6.3 \%)$. Patients of OTHERs were also more likely to have received trigger point injections than patients of PCPs or RHMs, and patients of OTHERs were more likely to have received chiropractic manipulation than patients of RHMs. Physicians strongly agreed that there was strong evidence in support of the use of patient education, with little variation across specialties. Both PCPs and OTHERs expressed more agreement than RHMs with respect to strong evidence supporting massage therapy in treating FM.

\section{Patient FM history and medical status}

Compared with patients of OTHERs, the patients of RHMs and PCPs reported having seen significantly fewer health care providers for symptoms prior to receiving a FM diagnosis, and they also reported that fewer physicians were currently involved in their FM treatment (Table 4). 
A

Long-term management of FM is another specialty's responsibility

Practice has set guidelines for treating FM

Confident in treating FM with alternative therapies 3.4

Limited by availability of treatments for $\mathrm{FM}^{*}$

Patient access to medications influences my treatment decisions

FM more difficult to treat than other pain

Treating FM is my responsibility

Believe in team approach to treating FM

Confident in treating FM with pharmacologic treatment

\section{B}

Symptoms patients suffer are psychosomatic

Diagnose FM in absence of other diagnoses

Diagnosis validates symptoms

I use ACR criteria to diagnose FM

FM patients take more time than average patient 4.2

Tender points are important in diagnosing FM

Recognizing FM is my responsibility

I am confident in diagnosing $\mathrm{FM}^{*}$

Psychological aspects of FM are important
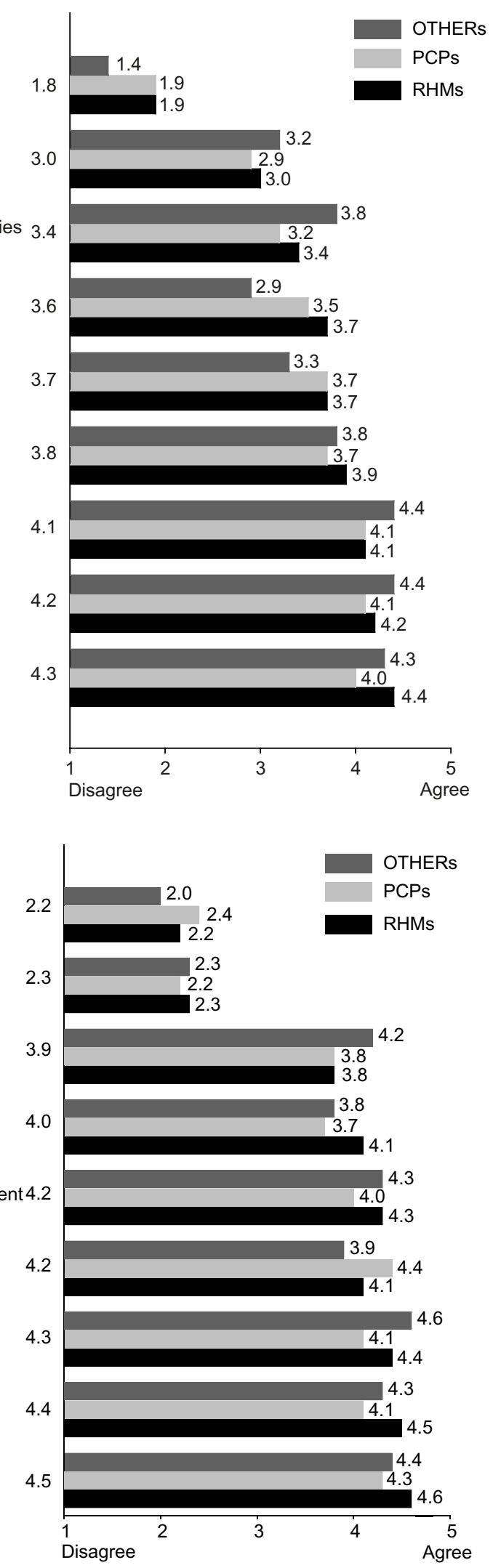

Figure I Physician attitudes toward treating (A) and diagnosing (B) FM.

Notes: Results reflect mean of answers based on a I-5 scale; $I=$ completely disagree, $5=$ completely agree. (A) *RHMs vs OTHERs, $P$-value $=0.02$. (B) *RHMs vs PCPs, $P$-value $=0.04$.

Abbreviations: ACR, American College of Rheumatology; FM, fibromyalgia; OTHERs, physicians practicing either pain or physical medicine, psychiatry, neurology, obstetrics and gynecology, osteopathy, or an unspecified specialty; PCPs, primary care physicians; RHMs, rheumatologists. 
Table 2 Pharmacologic treatments for FM: patients' use and physicians' perceptions of evidence

\begin{tabular}{|c|c|c|c|c|c|c|}
\hline \multirow[t]{2}{*}{ Patient use at baseline } & \multirow{2}{*}{$\begin{array}{l}\text { RHMs } \\
n=I, I 30 \\
n(\%)\end{array}$} & \multirow{2}{*}{$\begin{array}{l}\text { PCPs } \\
n=27 \mid\end{array}$} & \multirow{2}{*}{$\begin{array}{l}\text { OTHERs } \\
\mathrm{n}=299\end{array}$} & \multicolumn{3}{|l|}{$P$-value } \\
\hline & & & & $\begin{array}{l}\text { RHMs vs } \\
\text { PCPs }\end{array}$ & $\begin{array}{l}\text { RHMs vs } \\
\text { OTHERs }\end{array}$ & $\begin{array}{l}\text { PCPs vs } \\
\text { OTHERs }\end{array}$ \\
\hline Duloxetine & $306(27.1)$ & $44(16.2)$ & $106(35.5)$ & 0.001 & 0.001 & $<0.001$ \\
\hline NSAIDs & $276(24.4)$ & $125(46.1)$ & $54(18.1)$ & $<0.001$ & $<0.00$ I & $<0.001$ \\
\hline Pregabalin & $325(28.8)$ & $34(12.5)$ & $57(19.1)$ & $<0.001$ & $<0.001$ & - \\
\hline Opioids & $262(23.2)$ & $52(19.2)$ & $98(32.8)$ & - & - & 0.001 \\
\hline Tramadol & $170(15.0)$ & $53(19.6)$ & $37(12.4)$ & - & - & - \\
\hline Benzodiazepines & $176(15.6)$ & $38(14.0)$ & $45(15.1)$ & - & - & - \\
\hline SSRIs & $178(15.8)$ & $24(8.9)$ & $21(7.0)$ & 0.011 & 0.011 & - \\
\hline Non-BZD/sedative/hypnotics & $142(12.6)$ & $37(13.7)$ & $40(13.4)$ & - & - & - \\
\hline Cyclobenzaprine & $169(15.0)$ & $24(8.9)$ & $27(9.0)$ & 0.027 & 0.027 & - \\
\hline Gabapentin & $113(10.0)$ & $42(15.5)$ & $35(11.7)$ & 0.029 & 0.029 & - \\
\hline Milnacipran & $103(9.1)$ & $9(3.3)$ & $4 I(13.7)$ & 0.005 & 0.005 & $<0.001$ \\
\hline Muscle relaxants & $106(9.4)$ & $14(5.2)$ & $17(5.7)$ & - & - & - \\
\hline Other antidepressants & $87(7.7)$ & $30(11.1)$ & $15(5.0)$ & - & - & 0.022 \\
\hline Amitriptyline & $63(5.6)$ & $16(5.9)$ & $13(4.3)$ & - & - & - \\
\hline Stimulants & $43(3.8)$ & $14(5.2)$ & $31(10.4)$ & - & - & - \\
\hline Other TCAs & $59(5.2)$ & $9(3.3)$ & $\mathrm{I}(0.3)$ & - & - & 0.020 \\
\hline \multicolumn{7}{|c|}{ Physician-reported agreement: "There is strong evidence in the literature to support pharmacological therapies in treating FM" } \\
\hline \multirow[t]{2}{*}{$\begin{array}{l}\text { Physician-reported survey } \\
\text { response }\end{array}$} & $\begin{array}{l}\text { RHMs } \\
n=54\end{array}$ & $\begin{array}{l}\text { PCPs } \\
n=25\end{array}$ & $\begin{array}{l}\text { OTHERs } \\
n=12\end{array}$ & \multicolumn{3}{|l|}{$P$-value } \\
\hline & \multicolumn{3}{|c|}{ Average of I-5 scale mean (SD) } & $\begin{array}{l}\text { RHMs vs } \\
\text { PCPs }\end{array}$ & $\begin{array}{l}\text { RHMs vs } \\
\text { OTHERs }\end{array}$ & $\begin{array}{l}\text { PCPs vs } \\
\text { OTHERs }\end{array}$ \\
\hline Duloxetine & $4.2(0.8)$ & $3.4(1.0)$ & $4.2(0.9)$ & 0.003 & - & - \\
\hline NSAIDs & $2.8(1.1)$ & $3.1(1.0)$ & $2.9(1.1)$ & - & - & - \\
\hline Pregabalin & $4.4(0.8)$ & $4.1(0.9)$ & $4.4(0.7)$ & - & - & - \\
\hline Opioid analgesics & $2.1(1.1)$ & $2.6(1.0)$ & $2.7(1.0)$ & - & - & - \\
\hline Tramadol & $3.7(0.8)$ & $3.3(0.7)$ & $3.5(0.8)$ & - & - & - \\
\hline BZD hypnotics & $2.4(0.8)$ & $2.5(0.8)$ & $2.5(1.0)$ & - & - & - \\
\hline SSRIs & $3.7(0.8)$ & $3.7(0.8)$ & $3.5(0.9)$ & - & - & - \\
\hline Cyclobenzaprine & $3.5(0.7)$ & $3.2(0.9)$ & $2.9(0.8)$ & - & 0.034 & - \\
\hline Gabapentin & $3.4(0.9)$ & $3.6(0.9)$ & $3.3(1.0)$ & - & - & - \\
\hline Amitriptyline & $3.8(0.8)$ & $3.9(0.7)$ & $3.0(1.0)$ & - & 0.003 & 0.005 \\
\hline TCAs & $3.9(0.7)$ & $3.8(0.8)$ & $2.8(1.0)$ & - & $<0.001$ & 0.001 \\
\hline Venlafaxine & $3.8(0.9)$ & $3.4(0.8)$ & $3.5(0.7)$ & - & - & - \\
\hline Trazadone & $3.5(0.9)$ & $3.1(0.9)$ & $2.7(\mathrm{I} . \mathrm{I})$ & - & 0.023 & - \\
\hline Melatonin & $2.3(0.9)$ & $2.5(0.9)$ & $2.5(1.0)$ & - & - & - \\
\hline Growth hormone & $2.0(0.9)$ & $2.0(0.8)$ & $2.3(0.8)$ & - & - & - \\
\hline
\end{tabular}

Notes: (Top) Pharmacological treatment the patient has taken within the last 12 months including newly initiated and continuing therapies. (Bottom) Physician-reported agreement that there is strong evidence in the literature to support each of the following medications in the treatment of FM. Results reflect mean of answers based on a I-5 scale; I= completely disagree, $5=$ completely agree. "-" indicates not significant, $P>0.05$.

Abbreviations: BZD, benzodiazepine; FM, fibromyalgia; NSAIDs, nonsteroidal anti-inflammatory drugs; OTHERs, physicians practicing either pain or physical medicine, psychiatry, neurology, obstetrics and gynecology, osteopathy, or an unspecified specialty; PCPs, primary care physicians; RHMs, rheumatologists; SD, standard deviation; SSRIs, selective serotonin uptake inhibitors; TCAs, tricyclic antidepressants.

Patients from the REFLECTIONS study experienced an average of six concomitant chronic medical conditions (range: $0-25$ conditions) within the 3 years prior to study enrollment. ${ }^{6}$ Patients of RHMs reported significantly lower incidences of depression, sleep disorders, anxiety, and chronic fatigue syndrome than did patients of PCPs $(P<0.001)$ (Table 4). Patients of RHMs also reported significantly lower percentages of several other chronic conditions, compared with patients of OTHERs.

\section{Discussion}

In this study, we sought to identify consistencies and variations in physician and practice characteristics and attitudes toward diagnosing and treating FM using data from the REFLECTIONS study. Results from this study suggested that PCPs and RHMs shared generally similar personal and practice profile characteristics. Most investigators in the REFLECTIONS study were RHMs, followed by PCPs and OTHERs, which is consistent with the historical view that 
Table 3 Nonpharmacologic treatments for FM: patients' use and physicians' perceptions of evidence

\begin{tabular}{|c|c|c|c|c|c|c|}
\hline \multicolumn{7}{|c|}{ Patient reported: nonpharmacologic treatment for FM during 12 months prior to study enrollment } \\
\hline & \multirow{2}{*}{$\begin{array}{l}\text { RHMs } \\
\mathrm{n}=1,130 \\
\mathrm{n}(\%)\end{array}$} & \multirow{2}{*}{$\begin{array}{l}\text { PCPs } \\
n=27 \text { I } \\
n(\%)\end{array}$} & \multirow{2}{*}{$\begin{array}{l}\text { OTHERs } \\
\mathrm{n}=299 \\
\mathrm{n}(\%)\end{array}$} & \multicolumn{3}{|l|}{ P-value } \\
\hline & & & & $\begin{array}{l}\text { RHMs vs } \\
\text { PCPs }\end{array}$ & $\begin{array}{l}\text { RHMs vs } \\
\text { OTHERs }\end{array}$ & $\begin{array}{l}\text { PCPs vs } \\
\text { OTHERs }\end{array}$ \\
\hline Rest & I,03I (9I.2) & $237(87.5)$ & $279(93.3)$ & - & - & - \\
\hline Exercise & $1,018(90.1)$ & $231(85.2)$ & $272(91.0)$ & - & - & - \\
\hline Heat modalities & $870(77.0)$ & $189(69.7)$ & $225(75.3)$ & 0.038 & - & - \\
\hline Prayer, relaxation, meditation & $85 I(75.3)$ & $194(71.6)$ & $234(78.3)$ & - & - & - \\
\hline Distraction & $800(70.8)$ & $180(66.4)$ & $205(68.6)$ & - & - & - \\
\hline Cold therapy & $467(4 I .3)$ & III (4I.0) & $136(45.5)$ & - & - & - \\
\hline Counseling (including CBT) & $334(29.6)$ & $102(37.6)$ & $139(46.5)$ & 0.030 & $<0.001$ & - \\
\hline Massage, reflexology & $366(32.4)$ & $90(33.2)$ & I $34(44.8)$ & - & $<0.001$ & 0.014 \\
\hline Trigger point injections & $290(25.7)$ & $65(24.0)$ & III (37.I) & - & $<0.001$ & 0.002 \\
\hline Chiropractic manipulation & $246(21.8)$ & $64(23.6)$ & $93(31.1)$ & - & 0.002 & - \\
\hline TENS unit & $213(18.8)$ & $31(11.4)$ & $70(23.4)$ & 0.012 & - & 0.001 \\
\hline Acupuncture & $71(6.3)$ & $4 I(15.1)$ & $37(12.4)$ & $<0.001$ & 0.001 & - \\
\hline \multicolumn{7}{|c|}{ Physician-reported agreement: "There is strong evidence to support nonpharmacological therapies in treating FM" } \\
\hline & RHMs & PCPs & OTHERs & \multirow{2}{*}{\multicolumn{3}{|c|}{$P$-value }} \\
\hline & $\mathrm{n}=\mathbf{5 4}$ & $\mathrm{n}=\mathbf{2 5}$ & $n=12$ & & & \\
\hline & \multicolumn{3}{|c|}{ Average of I-5 scale mean (SD) } & $\begin{array}{l}\text { RHMs vs } \\
\text { PCPs }\end{array}$ & $\begin{array}{l}\text { RHMs vs } \\
\text { OTHERs }\end{array}$ & $\begin{array}{l}\text { PCPs vs } \\
\text { OTHERs }\end{array}$ \\
\hline Patient education & $4.6(0.6)$ & $4.3(0.7)$ & $4.3(0.7)$ & - & - & - \\
\hline Cardiovascular exercise & $4.2(0.7)$ & $4.0(0.8)$ & $3.6(1.0)$ & - & 0.036 & - \\
\hline CBT & $3.8(0.6)$ & $3.7(0.8)$ & $3.6(1.0)$ & - & - & - \\
\hline Biofeedback & $3.3(0.7)$ & $3.2(0.7)$ & $3.3(0.8)$ & - & - & - \\
\hline Massage & $2.9(0.9)$ & $3.5(0.8)$ & $3.6(0.9)$ & 0.010 & 0.036 & - \\
\hline Acupuncture & $2.9(0.9)$ & $3.0(0.9)$ & $2.8(I . I)$ & - & - & - \\
\hline Hypnotherapy & $2.2(0.7)$ & $2.7(0.6)$ & $2.8(0.9)$ & - & 0.033 & - \\
\hline Electrotherapy & $2.4(0.8)$ & $2.5(0.7)$ & $2.3(0.9)$ & - & - & - \\
\hline
\end{tabular}

Notes: (Top) Nonpharmacologic treatments for FM during 12 months prior to study enrollment. (Bottom) Physician-reported agreement that there is strong evidence in the literature to support each of the following interventions in the treatment of FM. Results reflect mean of answers based on a $\mathrm{I}-5 \mathrm{scale} ; \mathrm{I}=$ completely disagree, $5=$ completely agree. "-" indicates not significant, $P>0.05$.

Abbreviations: CBT, cognitive behavioral therapy; FM, fibromyalgia; OTHERs, physicians practicing either pain or physical medicine, psychiatry, neurology, obstetrics and gynecology, osteopathy, or an unspecified specialty; PCPs, primary care physicians; RHMs, rheumatologists; SD, standard deviation; TENS, transcutaneous electrical nerve stimulation.

FM is a rheumatologic condition. ${ }^{1,7}$ There were differences in the racial composition of patients by physician specialty, but this is likely due to the disproportionate numbers of study physicians in Puerto Rico practicing as PCPs.

Both RHMs and PCPs in our study agreed on evidence supporting nonpharmacological therapies in treating FM such as patient education, exercise, and cognitive behavioral therapy, which is consistent with other studies that have also reported that FM treatment should involve nonpharmacologic as well as pharmacologic treatments. ${ }^{8,9}$

Physicians from all cohorts reported using ACR criteria to guide their diagnosis of FM, intimating that specialists other than RHMs are also aware that FM can be positively diagnosed using 1990 ACR guidelines. ${ }^{7}$ While both RHMs and PCPs in this study generally expressed high levels of confidence in their ability to recognize and diagnose FM, the RHMs were significantly more confident than PCPs in their ability to diagnose FM.
Increasing reliance upon $2010 \mathrm{ACR}$ criteria which emphasize the assessment of patient symptoms over the tender point counts that played an important role in the 1990 ACR criteria may serve to close this gap in diagnostic confidence. ${ }^{10}$

Other studies have also suggested that PCPs are as equipped as specialists in the management of FM. ${ }^{11,12}$ Contrary to these findings, however, some studies ${ }^{13,14}$ have reported that the diagnosis and management of FM might pose a challenge to non-RHM specialists. Among Canadian physicians, $36 \%$ of general practitioners and $25 \%$ of specialists (anesthesiologists, neurologists, physiatrists, psychiatrists, and RHMs) expressed doubts in their ability to diagnose FM. ${ }^{14}$ In another study of physicians in Europe, Mexico, and South Korea, up to 61\% of PCPs compared with $31 \%$ of RHMs found it difficult to diagnose FM. ${ }^{13}$ Much of this seeming discrepancy likely reflects differences between the composition of the physician samples used in the 
Table 4 Patient clinical status at baseline

\begin{tabular}{|c|c|c|c|c|c|c|}
\hline \multirow[t]{2}{*}{ Fibromyalgia history } & \multicolumn{3}{|c|}{ Patients of: } & \multicolumn{3}{|l|}{$P$-value } \\
\hline & $\begin{array}{l}\text { RHMs } \\
\mathrm{n}=1,130\end{array}$ & $\begin{array}{l}\text { PCPs } \\
n=27 \mid\end{array}$ & $\begin{array}{l}\text { OTHERs } \\
n=299\end{array}$ & $\begin{array}{l}\text { RHMs vs } \\
\text { PCPs }\end{array}$ & $\begin{array}{l}\text { RHMs vs } \\
\text { OTHERs }\end{array}$ & $\begin{array}{l}\text { PCPs vs } \\
\text { OTHERs }\end{array}$ \\
\hline Years since first FM symptoms, mean (SD) & $10.0(9.2)$ & $9.5(8.3)$ & $10.5(9.6)$ & - & - & - \\
\hline Years since first FM diagnosis, mean (SD) & $5.6(6.4)$ & $5.3(5.6)$ & $5.8(6.6)$ & - & - & - \\
\hline \multicolumn{7}{|l|}{ before FM diagnosis, mean (SD) } \\
\hline $\begin{array}{l}\text { How many HCPs currently involved in FM } \\
\text { treatment, mean (SD) }\end{array}$ & $1.6(1.3)$ & $1.5(0.9)$ & $1.9(1.4)$ & - & 0.002 & 0.006 \\
\hline \multicolumn{7}{|c|}{${ }^{a}$ Chronic medical problems present during the 3 years prior to study enrollment: $\mathbf{n}(\%)$} \\
\hline Back pain & $888(80.7)$ & $223(82.9)$ & $246(83.4)$ & - & - & - \\
\hline Irritable bowel syndrome & $404(37.9)$ & $98(36.7)$ & $125(42.8)$ & - & - & - \\
\hline Abdominal pain & $380(35.3)$ & $100(37.3)$ & $124(42.3)$ & - & - & - \\
\hline Asthma & $239(22.2)$ & $66(24.4)$ & $59(20.1)$ & - & - & - \\
\hline Rheumatoid arthritis & 147 (13.9) & $24(9.0)$ & $38(13.1)$ & - & - & - \\
\hline Temporomandibular joint disorder & $228(21.6)$ & $51(19.5)$ & $67(23.4)$ & - & - & - \\
\hline Ulcer & $89(8.4)$ & $27(10.1)$ & $31(10.6)$ & - & - & - \\
\hline Heart disease & $89(8.3)$ & $25(9.3)$ & $18(6.2)$ & - & - & - \\
\hline Depression & $628(57.7)$ & $209(78.3)$ & $220(74.1)$ & $<0.001$ & $<0.001$ & - \\
\hline Arthritis & $709(65.0)$ & $170(62.7)$ & $146(49.2)$ & - & $<0.001$ & 0.003 \\
\hline Sleep disorders & $574(53.5)$ & $191(72.3)$ & $189(64.3)$ & $<0.001$ & 0.003 & - \\
\hline Anxiety & $563(52.0)$ & $181(67.5)$ & $202(68.2)$ & $<0.001$ & $<0.001$ & - \\
\hline Chronic fatigue syndrome & $407(38.2)$ & $160(60.4)$ & $157(53.6)$ & $<0.001$ & $<0.001$ & - \\
\hline Migraine & $387(36.0)$ & $101(38.0)$ & $132(45.1)$ & - & 0.014 & - \\
\hline Hypertension & $387(35.8)$ & $112(41.9)$ & $84(29.0)$ & - & - & 0.004 \\
\hline Diabetes & $114(10.6)$ & $38(14.2)$ & $23(7.9)$ & - & - & 0.050 \\
\hline
\end{tabular}

Notes: "-" indicates not significant, $P>0.05$; achronic medical problems reported by $>5 \%$ of patients in any cohort.

Abbreviations: FM, fibromyalgia; HCPs, health care providers; OTHERs, physicians practicing either pain or physical medicine, psychiatry, neurology, obstetrics and gynecology, osteopathy, or an unspecified specialty; PCPs, primary care physicians; RHMs, rheumatologists; SD, standard deviation.

referenced studies and investigators in the REFLECTIONS trial. Related to this finding was the fact that physicians across specialties in this study generally acknowledged that recognizing and treating FM was their responsibility, which suggests that at least a segment of the PCP population in the United States is caring for patients with FM themselves rather than: 1) routinely steering patients suspected of having FM to RHMs; or 2) approaching the condition as being purely musculoskeletal in nature. ${ }^{15}$

All cohorts disagreed that the FM diagnosis was made in the absence of other diagnoses, indicating that behavior of the physicians in this study is consistent with a proposal by Shir and Fitzcharles ${ }^{15}$ that emphasized that FM diagnosis should be based on a positive clinical diagnosis rather than on the exclusion of all other possibilities. The physicians in this study also showed strong agreement that the psychological aspects of FM are important, but did not agree that the symptoms were of psychosomatic origin, consistent with the notion that the symptoms of FM are "real" and that pain can be present in the absence of a readily measurable clinical abnormality. 7,16

Even though most physicians were more confident in prescribing pharmacological therapies, physicians tended to endorse a multidisciplinary approach to managing FM with a combination of pharmacologic and nonpharmacologic treatment modalities, similar to findings reported in previous studies. ${ }^{17,18}$ Significantly fewer patients of RHMs versus PCPs and RHMs versus OTHERs reported use of counseling and acupuncture for the treatment of FM in the year before study enrollment. There was a statistically significant difference across physician specialty where RHMs, compared with OTHERs, felt more limited by the availability of treatment options for patients with FM; RHMs less often reported support for the use of massage, compared with PCPs and OTHERs, and the use of hypnotherapy compared with OTHERs. This may be due to a lack of familiarity or comfort in implementing newer, less traditional nonpharmacologic measures into routine rheumatology practice. However, this may also reflect the smaller number of patients in the group of OTHERs and may not be clinically relevant.

The physicians accepted responsibility for the long-term management of their patients with FM and also expressed the belief that a team approach to treating FM was appropriate. Despite the existence of evidence-based treatment guidelines (American Pain Society in 2005; ${ }^{19}$ European League Against 
Rheumatism in $2008^{17}$ ), physicians were generally neutral about using set guidelines for treating FM.

Differences between these categories of physicians reinforce previously existing evidence that there is no universally agreed-upon intervention or treatment strategy/mix for treating all patients with FM. The PCPs and RHMs agree on the same top five recommended pharmacological treatments, but vary somewhat in their ordering within these top five treatments. The most commonly used pharmacologic treatments across all provider specialty groups included duloxetine, NSAIDs, pregabalin, and opioids. ${ }^{6}$ Patient symptoms related to clinical characteristics of severity of pain, depression, anxiety, disability, cognition, sleep disturbances, and fatigue were not significantly associated with treatment decisions. ${ }^{6}$ Treatment patterns may reflect current changes in the environment with the entry of pregabalin in June 2007 and duloxetine in June 2008 (just before the start of the study).

Current guidelines indicate strong evidence to support use of tricyclic antidepressants, duloxetine, milnacipran, pregabalin, and gabapentin for the treatment of FM. ${ }^{9}$ RHMs were considerably more likely to prescribe each of the three FDA-approved medications (duloxetine, pregabalin, and milnacipran) than were PCPs, suggesting that RHMs may be more familiar with recent guidelines and newly approved medications. Despite the apparent use of NSAIDs and opiates across specialties in this study, evidence for the efficacy of NSAIDs and opiates in patients with FM is lacking. ${ }^{20}$ In REFLECTIONS, use of NSAIDs was relatively high, but especially for patients of PCPs versus RHMs. This difference may be the result of greater non-FM pain-related comorbidities, and greater perceived need for direct treatment of specific comorbid symptoms in patients of PCPs. It could also be a response to patient preference or request for medication which, while lacking evidence, may be perceived as helpful to the individual patient. Use of opioids was higher in OTHERs than in PCPs, perhaps reflecting a more conservative stance among PCPs who are more likely to be involved in the longterm management of FM.

Notable was the small percentage of patients reporting the use of amitriptyline and other tricyclic antidepressants in comparison with the strong recommendations in favor of these medications in published guidelines and other studies. ${ }^{21}$ Similarly, physicians did not express strong agreement about their use. Benzodiazepines were also among the more frequently used medications in our study. Benzodiazepines and nonbenzodiazepine sedatives may have been prescribed more for their roles in sleep disturbances rather than for FM specifically. $^{22,23}$

\section{Limitations}

The study findings may not truly reflect a broad view of physician specialties that treat patients with FM for several reasons. The patients and physicians may not have been nationally representative even though the sample was large and included patients from 26 states and Puerto Rico. Most participating physicians were RHMs or PCPs who may have had greater interest and/or expertise in treating FM than OTHERs, including pain and physical medicine specialists, who were sparsely represented. The study was unable to tease out differences in physician treatment choices due to symptom severity. However, other, unmeasured factors may impact these differences. As indicated in the "Methods" section, the sample size for the group of OTHERs is too small and heterogeneous to draw conclusions from, but rather is included for completeness. In addition, the sample of providers is skewed towards male providers and RHMs, which may limit the generalizability of the results. Patients could be at any stage in the management cycle for FM; therefore, these findings may not be applicable to newly diagnosed patients with FM. There may be an increase in experimentwise type I error rate as no adjustments were made to account for making multiple pairwise comparisons.

\section{Conclusion}

The main findings in this study were that all groups of physicians seemed confident in their diagnosis of FM and see management of FM as their responsibility. RHMs are more likely to use the currently recommended therapies, with PCPs more often prescribing more traditional therapies. All groups of physicians use a mixture of pharmacological and nonpharmacological modalities. With FM being categorized as more of a pain syndrome rather than a musculoskeletal disease, and as the care of patients with FM shifts from RHMs to multiple physician specialties, examining predictors of FM treatment selection such as physician specialty may help improve FM treatment selection.

\section{Acknowledgments}

This study was funded through Eli Lilly and Company (Indianapolis, IN, USA). We thank Deborah D'Souza, $\mathrm{PhD}$, from inVentiv Health Clinical, LLC, for assistance with the preparation of the manuscript. Bill H McCarberg is retired from the Chronic Pain Management Program for Kaiser Permanente, Kaiser Permanente, and the Southern California Permanente Medical Group, Escondido, CA, USA. 


\section{Disclosure}

Stephen L Able, Rebecca L Robinson, and Madelaine Wohlreich are employees of, and minor shareholders in, Eli Lilly and Company. Kurt Kroenke is a consultant for Eli Lilly and Company. Philip Mease receives research funding, consulting fees, and is an honoraria speaker for Eli Lilly and Company and Pfizer, and receives research funding from Forest Pharmaceuticals. David A Williams is a consultant for Eli Lilly and Company. Yi Chen is a former employee of inVentiv Health Clinical. Bill H McCarberg is an advisor for Iroko, Pfizer, Zogenix, Collegium, Millennium, Mallinckrodt, Inspirion, Salix, Takeda, Depomed, Janssen, Kaleo, and AstraZeneca, and has the following stock holdings: Johnson and Johnson, Protein Design Labs, Biospecifics Technologies, Nektar Therapeutics, and Galena.

\section{References}

1. Wolfe F, Clauw DJ, Fitzcharles MA, et al. Fibromyalgia criteria and severity scales for clinical and epidemiological studies: a modification of the ACR Preliminary Diagnostic Criteria for Fibromyalgia. J Rheumatol. 2011;38(6):1113-1122.

2. Graham W. The fibrosits syndrome. Bull Rheum Dis. 1953;3(8):33-34.

3. Choy E, Perrot S, Leon T, et al. A patient survey of the impact of fibromyalgia and the journey to diagnosis. BMC Health Serv Res. 2010;10:102.

4. Ablin J, Neumann L, Buskila D. Pathogenesis of fibromyalgia - a review. Joint Bone Spine. 2008;75(3):273-279.

5. Yunus MB. Fibromyalgia and overlapping disorders: the unifying concept of central sensitivity syndromes. Semin Arthritis Rheum. 2007;36(6):339-356.

6. Robinson RL, Kroenke K, Mease P, et al. Burden of illness and treatment patterns for patients with fibromyalgia. Pain Med. 2012;13(10): 1366-1376.

7. Wolfe F, Smythe HA, Yunus MB, et al. The American College of Rheumatology 1990 Criteria for the Classification of Fibromyalgia. Report of the Multicenter Criteria Committee. Arthritis Rheum. 1990;33(2): $160-172$.

8. Fitzcharles MA, Yunus MB. The clinical concept of fibromyalgia as a changing paradigm in the past 20 years. Pain Res Treat. 2012;2012: 184835 .
9. Häuser W, Thieme K, Turk DC. Guidelines on the management of fibromyalgia syndrome - a systematic review. Eur J Pain. 2010;14(1): $5-10$.

10. Häuser W, Wolfe F. Diagnosis and diagnostic tests for fibromyalgia (syndrome). Rheumatismo. 2012;64(4):194-205.

11. McNett M, Goldenberg D, Schaefer C, et al. Treatment patterns among physician specialties in the management of fibromyalgia: results of a cross-sectional study in the United States. Curr Med Res Opin. 2011; 27(3):673-683.

12. Endresen GK. Fibromyalgia: a rheumatologic diagnosis? Rheumatol Int. 2007;27(11):999-1004.

13. Perrot S, Choy E, Petersel D, Ginovker A, Kramer E. Survey of physician experiences and perceptions about the diagnosis and treatment of fibromyalgia. BMC Health Serv Res. 2012;12:356.

14. Hayes SM, Myhal GC, Thornton JF, et al. Fibromyalgia and the therapeutic relationship: where uncertainty meets attitude. Pain Res Manag. 2010;15(6):385-391.

15. Shir Y, Fitzcharles MA. Should rheumatologists retain ownership of fibromyalgia? J Rheumatol. 2009;36(4):667-670.

16. Price DD, Staud R. Neurobiology of fibromyalgia syndrome. J Rheumatol Suppl. 2005;75:22-28.

17. Carville SF, Arendt-Nielsen L, Bliddal H, et al. EULAR evidence-based recommendations for the management of fibromyalgia syndrome. Ann Rheum Dis. 2008;67(4):536-541.

18. Scascighini L, Toma V, Dober-Spielmann S, Sprott H. Multidisciplinary treatment for chronic pain: a systematic review of interventions and outcomes. Rheumatology (Oxford). 2008;47(5):670-678.

19. Burckhardt C, Goldenberg D, Crofford L, Gerwin R, Gowans S, Kackson K. Guideline for the Management of Fibromyalgia Syndrome Pain in Adults and Children. APS Clinical Practice Guideline Series, No 4. Glenview: American Pain Society; 2005. Available from http://apps. americanpainsociety.org/Default.aspx TabID $=251 \&$ ProductId $=473$. Accessed September 15, 2015.

20. Mease P, Arnold LM, Bennett R, et al. Fibromyalgia syndrome. $J$ Rheumatol. 2007;34(6):1415-1425.

21. Nishishinya B, Urrútia G, Walitt B, et al. Amitriptyline in the treatment of fibromyalgia: a systematic review of its efficacy. Rheumatology (Oxford). 2008;47(12):1741-1746.

22. Goldenberg DL. Pharmacological treatment of fibromyalgia and other chronic musculoskeletal pain. Best Pract Res Clin Rheumatol. 2007;21(3):499-511.

23. Goldenberg DL, Burckhardt C, Crofford L. Management of fibromyalgia syndrome. JAMA. 2004;292(19):2388-2395.
Pragmatic and Observational Research

\section{Publish your work in this journal}

Pragmatic and Observational Research is an international, peer-reviewed, open access journal that publishes data from studies designed to reflect more closely medical interventions in real-world clinical practice compared with classical randomized controlled trials (RCTs). The manuscript management system is completely online and includes a very quick and fair peer-review

\section{Dovepress}

system. Visit http://www.dovepress.com/testimonials.php to read real quotes from published authors. 